\title{
Sintering of Nd-Fe-B Magnets from Dy Coated Powder
}

\author{
Jin Woo Kim and Young Do Kim* \\ Department of Materials Science and Engineering, Hanyang University, Seoul 133-791, Korea
}

(Received June 3, 2013; Accepted June 24, 2013)

\begin{abstract}
High-coercive (Nd,Dy)-Fe-B magnets were fabricated via dysprosium coating on Nd-Fe-B powder. The sputtering coating process of $\mathrm{Nd}-\mathrm{Fe}-\mathrm{B}$ powder yielded samples with densities greater than $98 \%$. $(\mathrm{Nd}, \mathrm{Dy})_{2} \mathrm{Fe}_{14} \mathrm{~B}$ phases may have effectively penetrated into the boundaries between neighboring $\mathrm{Nd}_{2} \mathrm{Fe}_{14} \mathrm{~B}$ grains during the sputtering coating process, thereby forming a $(\mathrm{Nd}, \mathrm{Dy})_{2} \mathrm{Fe}_{14} \mathrm{~B}$ phase at the grain boundary. The maximum thickness of the Dy shell was approximately $70 \mathrm{~nm}$. The maximum coercivity of the Dy sputter coated samples(sintered samples) increased from 1162.42 to $2020.70 \mathrm{kA} / \mathrm{m}$. The microstructures of the $(\mathrm{Nd}, \mathrm{Dy})_{2} \mathrm{Fe}_{14} \mathrm{~B}$ phases were effectively controlled, resulting in improved magnetic properties. The increase in coercivity of the Nd-Fe-B sintered magnet is discussed from a microstructural point of view.
\end{abstract}

Keywords: Nd-Fe-B sintered magnet, Core-shell type structure, Dy coating, Coercivity, Sputter coating process

\section{Introduction}

Sintered Nd-Fe-B magnets have been extensively studied because of their excellent magnetic properties. One increasingly important area of application of sintered $\mathrm{Nd}-$ Fe-B magnets involves their use in motors for hybrid/electric vehicles [1-3]. These motors must operate at temperatures up to $200^{\circ} \mathrm{C}$ because of the heat generated by the high rotational speeds and eddy current loss in the core. The application of sintered Nd-Fe-B magnets in hybrid/ electric vehicle motors is limited because these materials typically have low Curie temperatures and thermal coercivity degradation issues at elevated temperatures [4].

In all types of hard-magnetic materials, changes in magnetic flux and other magnetic characteristics are due to both irreversible and reversible losses. One potential solution to overcome thermal magnetic degradation of sintered Nd-Fe-B magnets at elevated temperatures involves enhancing the coercivity of these materials [5].

There are two possible approaches for developing coercivity at high temperatures: either improving the intrinsic temperature dependence of the materials, or developing sufficient coercivity at room temperature so that enough coercivity remains when the magnet is exposed to high temperatures. Unfortunately, the intrinsic properties of Nd-Fe-B magnets are very difficult to change. However, the addition of heavy rare earth (RE) elements such as Dy or $\mathrm{Tb}$ is known to enhance coercivity in Nd-Fe-B magnets, and this effect has been attributed to an increase in the magnetic anisotropy field on the addition of small amounts of heavy rare earth elements [3, 6-8].

$\mathrm{Nd}-\mathrm{Fe}-\mathrm{B}$ magnets have developed a technique to allocate heavy rare earth elements(HREE) that produce a large anisotropy field, such as HREE, along the grain boundaries and then into the outer shell of the $\mathrm{RE}_{2} \mathrm{Fe}_{14} \mathrm{~B}$ grains, resulting in a core-shell type structure (Fig. 1). Because Nd-Fe-B magnets generate coercivity on the basis of a nucleationtype coercivity mechanism, the anisotropy field only needs to be increased locally in the outer shell of the grains to a depth of much less than a micron, as any additional heavy rare earth in the $\mathrm{RE}_{2} \mathrm{Fe}_{14} \mathrm{~B}$ grains will simply contribute to a lower value of magnetization. This core-shell structure is produced by putting the heavy rare earth in some form [3]. For example, W.Q. Liu made sintered magnets by mixing R-Fe-B material powder and Dy nanoparticles [6], while K. Hirota suggested a method to coat sintered magnets with Dy powder and then heat treat the magnets in order to diffuse the Dy into the sintered magnets [7]. In summary,

*Corresponding Author: Young Do Kim, TEL: +82-2-2220-0408, FAX: +82-2-2220-4230, E-mail: ydkim1@hanyang.ac.kr 


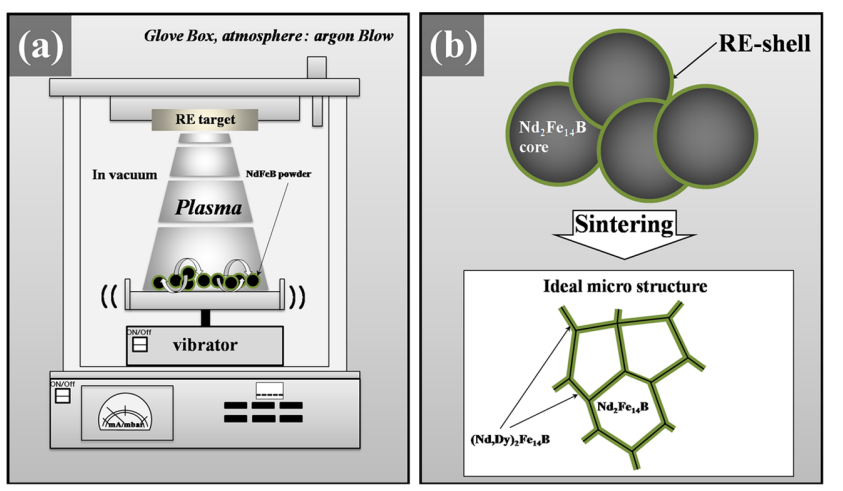

Fig. 1. (a) Sputtering equipment used for the Nd-Fe-B powder coating, (b) ideal core-shell powder shapes (upper diagram) and microstructures obtained when the core-shell powder was sintered (lower diagram).

approaches involving direct physical mixtures of RE-FeB material powder with Dy nanoparticles [6] and coating of sintered magnets with Dy powder followed by a thermal treatment (to favor diffusion of the rare earth element into the sintered magnet material) [7] have been previously proposed.

However, these methods lead to an uneven distribution of Dy and uncontrolled and limited (10 $\mu \mathrm{m}$ from the surface) diffusion of rare earth into sintered magnet materials. Consequently, these existing methods do not provide sufficient improvement of coercivity in sintered magnet materials. Furthermore, in addition to increasing the cost of the final material, adding rare earth elements has the further disadvantage of reducing the remanence $[3,6]$, since heavy rare earths couple anti-ferromagnetically with the $\mathrm{Fe}$ in the $\mathrm{RE}_{2} \mathrm{Fe}_{14} \mathrm{~B}$ lattice; hence these elements should be added in limited amounts. Thus there is a growing need for sintered magnet manufacturing technologies that achieve uniform addition of small amounts of heavy rare earth elements.

In this study, we demonstrated a sputter coating process to produce uniform $\mathrm{RE}(\mathrm{Dy})$ core-shell structures on sintered magnet powder grain boundaries. This methodology achieves significant changes in the microstructures and magnetic properties of the sintered samples. The increase in coercivity of the Nd-Fe-B sintered magnet is discussed from a microstructural perspective.

\section{Experimental Procedure}

Nd-Fe-B alloy strips with a chemical composition of
$\mathrm{Nd}_{14} \mathrm{Fe}_{77} \mathrm{TM}_{3} \mathrm{~B}_{6}(\mathrm{TM}=\mathrm{Co}, \mathrm{Cu}, \mathrm{Al}, \mathrm{Nb}$; at\%) were formed by strip casting after melting by inductive heating of elemental materials in a vacuum atmosphere. The Nd-Fe-B alloy strips were exposed to a hydrogen-decrepitation process and then jet-milled under an $\mathrm{N}_{2}$ atmosphere to generate a powder with an average particle size of 5.0 $\mu \mathrm{m}$. Fig. 1 shows a schematic diagram of the sputtering equipment used for powder coating and the core-shell powder shapes and ideal microstructures created after the sputter coating process. The jet-milled powder was coated with Dy by installing a Dy target in the sputter coating equipment (Fig. 1(a)). A vacuum level of $\leq 2.4$ $\times 10^{-3}$ Torr was maintained to induce the formation of plasma. The $\mathrm{Nd}_{2} \mathrm{Fe}_{14} \mathrm{~B}$ powder (core powder) was then placed on the powder tray and subsequently coated with Dy for $2.48 \mathrm{wt} \%$ by applying a continuous vibration to the tray, and the Dy-coated Nd-Fe-B powder was magnetically aligned at $2.0 \mathrm{MA} / \mathrm{m}$ and compacted at $50 \mathrm{MPa}$ to achieve dimensions of $10 \times 10 \times 5 \mathrm{~mm}^{3}$. The sintering process was then carried out at $1070^{\circ} \mathrm{C}$ for $4 \mathrm{~h}$, followed by heat treatment at $850^{\circ} \mathrm{C}$ for $2 \mathrm{~h}$ and at $500^{\circ} \mathrm{C}$ for $2 \mathrm{~h}$ in a vacuum atmosphere $\left(<1.2 \times 10^{-6}\right.$ Torr $)$. As depicted in Fig. 1(b), sintering of the Dy-coated $\mathrm{Nd}_{2} \mathrm{Fe}_{14} \mathrm{~B}$ powder allows for the effective formation of Dy core-shell structures as well as $(\mathrm{Nd}, \mathrm{Dy})_{2} \mathrm{Fe}_{14} \mathrm{~B}$ phases around the $\mathrm{Nd}_{2} \mathrm{Fe}_{14} \mathrm{~B}$ grains. Total rare earth content of powder was measured by inductively coupled plasma-atomic emission spectroscopy (ICP-AES).

The microstructures of the powder samples were observed by scanning electron microscopy (SEM) and energy-dispersive X-ray spectroscopy (EDS), while the microstructures of the sintered samples were analyzed using an Electron Probe Micro Analyzer (EPMA). The magnetic properties of the prepared materials were measured with a B-H loop tracer (Magnet-Physik Permagraph C-300) at room temperature.

\section{Results and Discussion}

Fig. 2(a) and (b) show cross-sectional SEM (BSE) images of the coated powder, while Fig. 2(c) shows the EDS point analysis of the shell (point A) and core (point B) parts of the coated powder. A Dy sputter coating process was applied for $2.48 \mathrm{wt} \%$ on this core powder, resulting in whitish gray shell structures, which were 

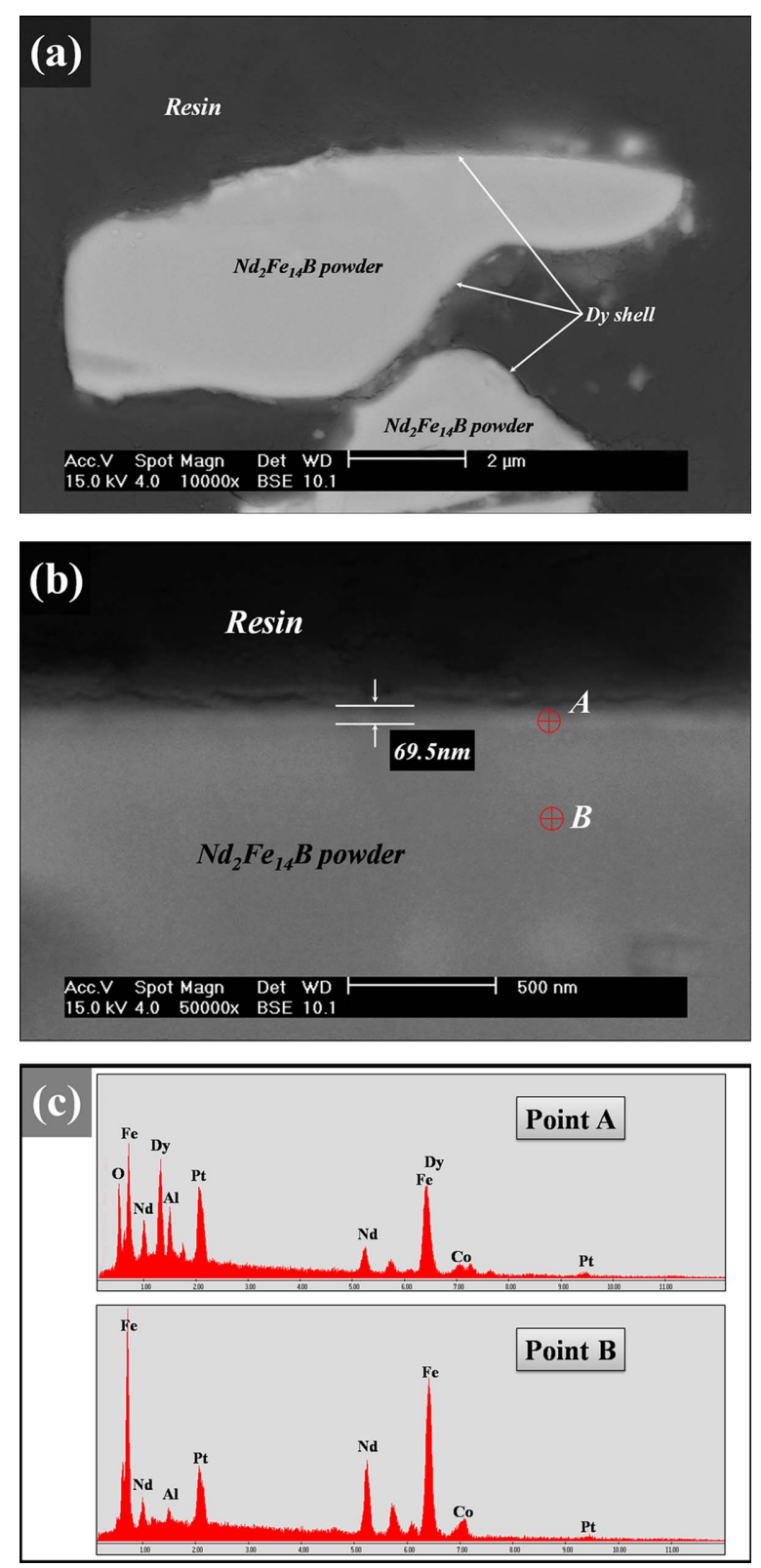

Fig. 2. Analysis of the microstructure of the powder produced by the sputter coating process: (a) and (b) cross-section SEM (BSE) images, and (c) EDS point mapping images of the shell (point A) and core (point B) parts of the coated powder. assumed to be a different phase, formed on the gray $\mathrm{Nd}_{2} \mathrm{Fe}_{14} \mathrm{~B}$ core powder. The thickness of the Dy shell was approximately $69.5 \mathrm{~nm}$, as indicated in Fig. 2(b). The formation of Dy-shell structures by the sputter coating process was confirmed by EDS point analysis, which showed evidence of the presence of Dy (Fig. 2(b), point A) and of the reduction of the relative $\mathrm{Fe}$ and $\mathrm{Nd}$ content compared to the core section (Fig. 2(b), point B). Therefore, proper microstructure control at the initial powder stage can facilitate the formation of Dy shells on $\mathrm{Nd}_{2} \mathrm{Fe}_{14} \mathrm{~B}$ cores during the final sintering step.

Fig. 3 shows SEM (BSE) images of the sintered powder with different Dy contents. When compared to a sintered sample using non-coated powder (Fig. 3(a)), the sample using Dy-coated powder (Fig. 3(b)) showed a continuous $\mathrm{Nd}$-rich phase connecting the grain boundaries. Fig. 4 shows demagnetization curves of the Dycoated specimens and a non-coated sintered specimen. Dy-coated specimens had reasonably higher coercivity and lower remanence than non-coated ones.

In general, the remanence of the $\mathrm{Dy}_{2} \mathrm{Fe}_{14} \mathrm{~B}$ phase was lower than that of the $\mathrm{Nd}_{2} \mathrm{Fe}_{14} \mathrm{~B}$ phase. The total remanence of the $(\mathrm{Nd}, \mathrm{Dy})-\mathrm{Fe}-\mathrm{B}$ magnets decreased as a result of the increase in $\mathrm{Dy}_{2} \mathrm{Fe}_{14} \mathrm{~B}$ phase with Dy content $[6,7,9]$. In the Dy-coated specimens, the remanence did not decrease greatly compared to the non-coated sintered specimen. As shown in Table 1, such a minimal decrease in remanence seems to be due to the increase in total rare earth due to the added Dy content. In this case, even though the remanence was decreased due to the increase in both the total rare earth material and the Dy content, it was still superior to others with similar compositions [6]. In particular, after heat treatment, the coated specimen showed a noticeable improvement in the coercive value
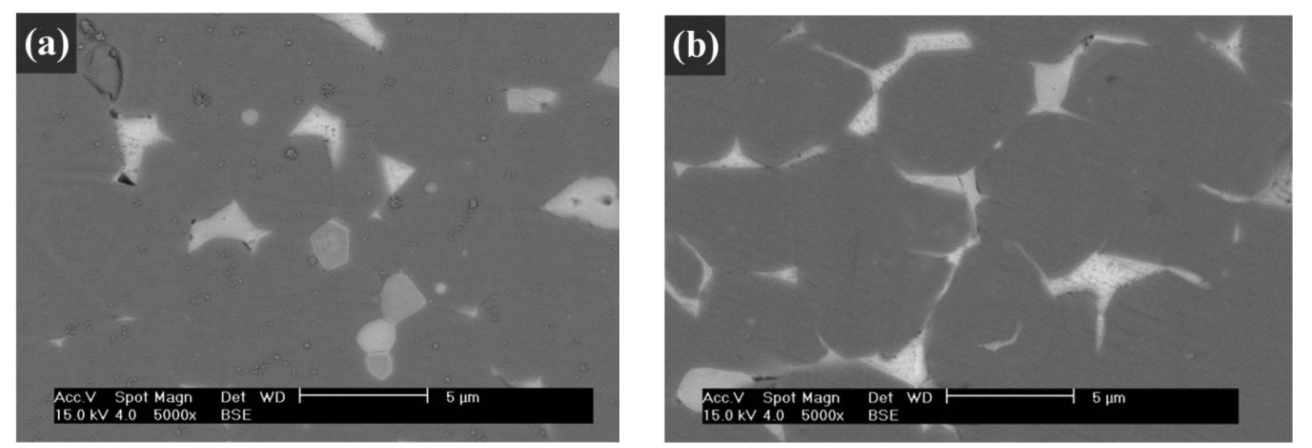

Fig. 3. SEM (BSE) images of the sintered powder at different Dy content: (a) 0 wt\%(non-coated) and (b) 2.48 wt $\%$ (coated). 
Table 1. Magnetic properties, total rare earth content, and relative density of each sample

\begin{tabular}{clllccccc}
\hline \hline Process & Specimen & $\begin{array}{c}\text { Dy } \\
(\mathrm{wt} \%)\end{array}$ & $\begin{array}{c}\mathrm{Nd} \\
(\mathrm{wt} \%)\end{array}$ & $\begin{array}{c}\text { Total RE } \\
(\mathrm{wt} \%)\end{array}$ & $\begin{array}{c}\mathrm{H}_{\mathrm{ci}} \\
(\mathrm{kA} / \mathrm{m})\end{array}$ & $\begin{array}{c}\mathrm{B}_{\mathrm{r}} \\
(\mathrm{T})\end{array}$ & $\begin{array}{c}\text { (BH)max } \\
(\mathrm{MGOe})\end{array}$ & $\begin{array}{c}\text { Density } \\
\left(\mathrm{g} / \mathrm{cm}^{3}\right)\end{array}$ \\
\hline \multirow{2}{*}{ Non-coated } & As sintered & 0 & 32 & 32 & 936.38 & 1.39 & 47.4 & 7.64 \\
& After HT & 0 & 32 & 32 & 1162.42 & 1.39 & 47.55 & 7.64 \\
\hline \multirow{2}{*}{ Coated } & As sintered & 2.48 & 31.2 & 33.68 & 1075.16 & 1.31 & 42.40 & 7.64 \\
& After HT & 2.48 & 31.2 & 33.68 & 2020.70 & 1.30 & 42.75 & 7.64 \\
\hline
\end{tabular}

*HT: Heat treatment, *Theoretical density: $7.68 \mathrm{~g} / \mathrm{cm}^{3}$

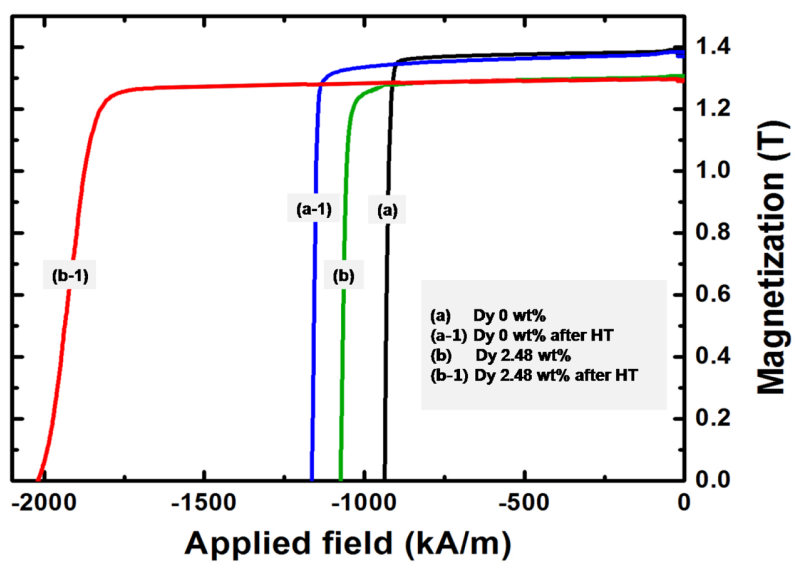

Fig. 4. Demagnetization curves of non-coated and Dy-coated specimens with heat treatment (HT).

of $858.28 \mathrm{kA} / \mathrm{m}$ as compared to the non-coated specimen.

The coercivity of Dy-coated specimens increased remarkably after heat treatment. Comparably, the noncoated specimens also showed an increase in coercivity of $226.04 \mathrm{kA} / \mathrm{m}$. It has been previously reported that the increase of coercivity with around $2.5 \mathrm{wt} \%$ Dy content is $400-450 \mathrm{kA} / \mathrm{m}$ [10]. However, in the case of the coated specimen, the coercivity increased over two times com- pared with that of a conventional Dy-alloyed magnet. The remarkable increase in coercivity of the coated specimens can be attributed to the sintering of the powder component of the fabricated core-shell structure caused by the heat treatment process. During this process, an exchange between the $\mathrm{Nd}_{2} \mathrm{Fe}_{14} \mathrm{~B}$ phase of the core and the Dy phase of the shell occurred, thereby forming a $(\mathrm{Nd}, \mathrm{Dy})_{2} \mathrm{Fe}_{14} \mathrm{~B}$ phase at the grain boundary [10]. In general, this phase formed at the grain boundary shows a larger $H_{A}$ than does the core phase, thus enhancing the $H_{c i}$ values of the Nd-Fe-B magnets [6].

Fig. 5 shows SEM images of non-coated and Dycoated specimens $(2.48 \mathrm{wt} \%)$ and a related EPMA mapping image. The microstructures in the BSE image in Figs. 5(a, f) are typical of a Nd-Fe-B sintered magnet, and they consist of a $\mathrm{Nd}_{2} \mathrm{Fe}_{14} \mathrm{~B}$ main phase (gray color) and a Nd-rich interface phase (white color). Figs. 5(b-e and g-j) show the EPMA mapping results for non-coated and Dy-coated specimens (2.48 wt \%).

The Dy-coated specimens show Nd-rich (NdOx) phases infiltrating along the $\mathrm{Nd}_{2} \mathrm{Fe}_{14} \mathrm{~B}$ grain boundaries (continuous GBP phase). Furthermore, because the grain
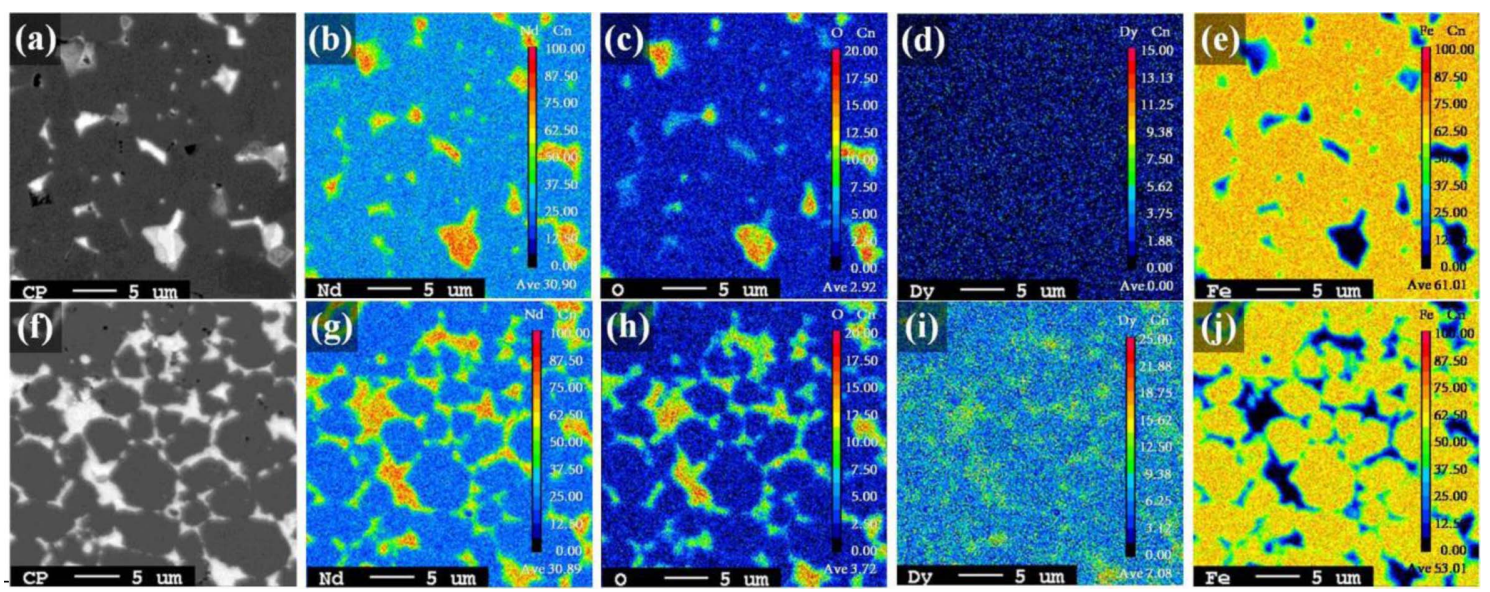

Fig. 5. Secondary electrons image and EPMA mapping results of non-coated (a-e) and Dy-coated specimens (f-j): (a), (f) back-

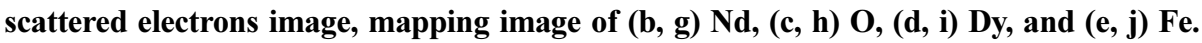


boundaries of the Nd-rich ( $\mathrm{NdOx}$ ) phases are surrounded with Dy, a (Nd,Dy) $)_{2} \mathrm{Fe}_{14} \mathrm{~B}$ phase may be formed. In noncoated specimens, however, the $\mathrm{Nd}_{2} \mathrm{Fe}_{14} \mathrm{~B}$ (hard magnet phase) cannot be isolated fully due to the Nd-rich, which exists locally in the triple junction phase.

The results presented in Figs. 4 and 5 clearly indicate that the powder fabricated by our sputter coating process effectively isolated the surroundings of the $\mathrm{Nd}_{2} \mathrm{Fe}_{14} \mathrm{~B}$ core phase, resulting in a new material with improved coercivity characteristics. Both the addition of a heavy $\mathrm{RE}$ element such as Dy and the formation of a $(\mathrm{Nd}, \mathrm{Dy})_{2} \mathrm{Fe}_{14} \mathrm{~B}$ phase are likely to restrain the antiferromagnetic coupling of Dy atoms with $\mathrm{Fe}$ atoms. In addition, it has been suggested previously that this $(\mathrm{Nd}, \mathrm{Dy})_{2} \mathrm{Fe}_{14} \mathrm{~B}$ phase plays an important role in decreasing the nucleation sites of reverse domains and in the isolation of $\mathrm{Nd}_{2} \mathrm{Fe}_{14} \mathrm{~B}$ grains [11].

\section{Conclusions}

This study describes a Dy sputtering process for coating $\mathrm{Nd}_{2} \mathrm{Fe}_{14} \mathrm{~B}$ powders with Dy to manufacture highcoercivity (Nd, Dy)-Fe-B sintered magnets in the form of core-shell structures. These magnets showed high relative density $(99 \%)$ and coercivity $(2020.70 \mathrm{kA} / \mathrm{m})$ values while preserving an average remanence of $1.32 \mathrm{~T}$. A comparison of these values to those obtained for noncoated samples revealed a similar relative density and remanence values and an enhanced coercivity. Furthermore, the (Nd,Dy) $)_{2} \mathrm{Fe}_{14} \mathrm{~B}$ shell layer, which formed effectively around the $\mathrm{Nd}_{2} \mathrm{Fe}_{14} \mathrm{~B}$ phase along the grain boundaries, completely enhanced the anisotropy field of the hard magnet phase, while the continuous $(\mathrm{Nd}, \mathrm{Dy})_{2} \mathrm{Fe}_{14} \mathrm{~B}$ phase contributed to the increase in coercivity.

\section{Acknowledgments}

- This work was supported by the Strategic Core Material Technology Development Program (No. 10043780) funded by the Ministry of Knowledge Economy (MKE, Korea).

- This work was supported Korea Institute for Rare metals (KIRAM) funded by Korea Institute of Industrial Technology (KITECH, Korea)

\section{References}

[1] M. Sagawa, S. Fujimura, N. Togawa, H. Yamamoto and Y. Matsuura: J. Appl. Phys., 55 (1984) 2083.

[2] H. J. Wang, Z. H. Guo, A. H. Li, X. M. Li and W. Li: J. Magn. Magn. Mater., 303 (2006) e392.

[3] M. Soderznik, K. Z. Rozman, S.Kobe and P. McGuiness: Intermetallics., 23 (2012) 158.

[4] W. F. Li, T. Ohkubo, K. Hono and M. Sagawa: J. Magn. Mater., 321 (2009) 1100.

[5] I. D. Kosobudskii, V. P. Sevostyanov and M. V. Kuznetsov: Inorg. Mater., 36 (6) (2000) 584.

[6] W. Q. Liu, H. Sun, X. F. Yi, X. C. Liu, D. T. Zhang, M. Yue and J. X. Zhang: J. Alloys Compd., 501 (2010) 67.

[7] K. Hirota, H. Nakamura, T. Minowa and M. Honshima: IEEE Trans. Magn., 42 (10) (2006). 2909.

[8] C. H. de Groot, K. H. J. Buschow and F. R. de Boer: J. Appl. Phys., 83 (1998) 388.

[9] Gaolin Yan, P. J. McGuiness, J. P. G. Farr and I. R. Harris: J. Alloys Compd., 491 (2010) L20.

[10] Fang Xu, Lanting Zhang, Xianping Dong, Qiongzhen Liu and Matahiro Komuro: Scr. Mater., 64 (2011) 1137.

[11] K. Raviprasad, M. Funakoshi and d M. Umemoto: J. Appl. Phys., 83(2) (1998) 921. 